\title{
25 Research Square \\ Open Globe Injury related to Road Traffic Accident: a Retrospective Study
}

\section{Phit Upaphong}

Chiang Mai University

\section{Pongsant Supreeyathitikul}

Maharaj Nakorn Chiang Mai Hospital

Janejit Choovuthayakorn ( $\nabla$ janejit.c@cmu.ac.th )

Chiang Mai University https://orcid.org/0000-0001-5972-0270

\section{Research article}

Keywords: road traffic injury, open globe injury, vehicle-related eye injury

Posted Date: December 17th, 2019

DOI: https://doi.org/10.21203/rs.2.18776/v1

License: (c) (i) This work is licensed under a Creative Commons Attribution 4.0 International License. Read Full License 


\section{Abstract}

\section{Background}

To evaluate epidemiology, clinical characteristics and outcomes of patients who sustained road trafficrelated open globe injury (OGI)

\section{Methods}

Medical records of all road traffic-related OGI patients who were admitted to the hospital from January 2006 to December 2016 were retrospectively reviewed. Data including age, gender, vehicle type, initial ocular presentation, and final visual outcome were extracted.

\section{Results}

Among the overall causes of OGI, road traffic-related accidents comprised 92/978 (9\%) of cases. Of these, ten $(11 \%)$ patients acquired bilateral eye injuries and $72(78 \%)$ were male. Nearly half of the injuries (51\%) occurred in the 20-39 years old age group and the majority of cases $(59 \%)$ involved automobile transportation. Globe rupture, 48 (47\%) eyes, occurred in a similar proportion of penetration, $46(45 \%)$ eyes. Following treatments, LogMAR visual acuity (VA) significantly improved from a median (interquartile range) of $2.3(1.9-2.3)$ to $1.7(0.3-3.0)$, at the final follow-up appointment. Presence of relative afferent pupillary defect and presence of retinal detachment were predictors for poor final visual outcomes.

\section{Conclusions}

This study provides information regarding road traffic-related OGI that had a high prevalence in young. The risky transportation mode were motorcycles in teenager and automobiles in young adult. A considerable proportion of impaired final VA might have a significant impact on the socio-economic system. Establishing effective safety education and encouraging regular adherence to road safety behaviors are challenging issues that need more action.

\section{Background}

Open globe injury (OGI), defined as a full-thickness laceration of the eye wall, is one of the main conditions leading to an acquired visual disability and a subsequent decline in quality of life [1]. Previous studies from New Zealand and Singapore estimated the annual incidence of OGI to be 2.8 and 3.7 per 100,000 population $[2,3]$. There are several etiologies of OGI which have been reported with different characteristics [4-6]. Among these, road traffic-related OGI has been consistently described as one of a common condition needed for more preventive actions [7-11]. Within the overall cases of OGI, about 2 to $17.6 \%$ were related to road traffic accident [12-16]. 
As there is limited data, this study aimed to assess the demographics, ophthalmic clinical characteristics, and outcomes of severe open globe injuries related to road traffic accidents in a tertiary referral center. The findings may contribute useful data in establishing appropriate health care education for road trafficrelated $\mathrm{OGI}$.

\section{Materials And Methods}

This retrospective study was performed at Chiang Mai University Hospital, a tertiary referral center in Northern Thailand and conducted in accordance with the Declaration of Helsinki. The protocol was considered and approved by the Research and Ethics Committee, Faculty of Medicine, Chiang Mai University.

The medical records of OGI patients who were admitted from January 2006 to December 2016 were evaluated. Then, the records of injury related to road traffic accidents were identified and reviewed in detail. The collected data included patients' demographics comprising age, gender, laterality, and mechanism of injury. Ocular features at initial examination including visual acuity (VA), zone and location of injury, wound length, presence of relative afferent pupillary defect (RAPD), anterior and posterior segment abnormalities, presence of endophthalmitis, and associated adnexal injury were noted. Zone of injury was classified according to ocular trauma classification into injury limited to cornea and corneoscleral limbus (Zone I), injury at anterior five $\mathrm{mm}$ of sclera (Zone II), and injury that extended more than five $\mathrm{mm}$ from the limbus into posterior sclera (Zone III) [17]. An ocular trauma score was calculated from the initial VA, and presence of the following features: globe rupture, endophthalmitis, perforating injury, retinal detachment, and RAPD [18]. The mechanisms of injury were divided by the Birmingham Eye Trauma Terminology System (BETT) into 4 types: globe rupture (referred to eye injury by blunt force), penetration and perforation (referred to eye injury by sharp force), and intraocular foreign body (IOFB) [19]. Ophthalmic management and final VA at last follow-up were evaluated. The improvement or worsening of one or more Snellen VA line at the final compared to presenting visit was evaluated.

\section{Statistical Analyses}

Patients' demographics were presented by descriptive analysis. Categorical data comparison was performed by Chi-squared or Fischer exact test. For continuous data comparison, Kruskal Wallis test and Wilcoxon signed-rank test were used as appropriate. Snellen VA was converted to the Logarithm of the Minimum Angle of Resolution (LogMAR) for VA analysis. Poor final VA was defined as the Snellen VA worse than 20/400. Multivariable regression analysis for poor final VA was adjusted for age, gender, initial VA, mechanisms of injury, uveal tissue prolapse, vitreous prolapse, presence of retinal detachment, presence of endophthalmitis, presence of lens injury, and presence of RAPD with backward LR method. A statistical significance was considered as $P<0.05$. All analyses were performed using SPSS version 24 (IBM Corp., Armonk, NY, USA).

\section{Results}


From 978 hospitalized OGI cases, there were 92 (9.4\%) patients (102 eyes) sustained injury related to a road traffic accident with a median (interquartile range) follow-up of nine (3.4 to 31) months. These patients had a mean (SD) age of 33.9 (13.8) years (range, 5 to 84 years). Male presented in 72/92 (78.3\%) patients. The incidence of injury by month is illustrated in Fig 1 with no distinct pattern observed. Considering the frequency of injury by age groups, the peak incidence of injury (47/92, 51.1\%) was noted in the 20-39 years age group. Noticeably, a proportion of motorcycle-related accident was highest in patients aged less than 20 years $(9 / 16,56.3 \%)$, while automobile-related accident was a predominant vehicle in other age groups, Fig 2. Patients' demographics are documented in Table 1.

Regarding mechanisms of injury, 48/102 (47.1\%) eyes had globe rupture, followed by penetration in $46 / 102$ (45.1\%), and IOFB in 8/102 (7.8\%). There were no patients with perforation. A median (interquartile range) time-lapse from injury to the hospital was 23 (5.3-114) hours. At initial examination, the median (IQR) presenting LogMAR VA was 2.3 (1.9 to 2.3) with the mean (SD) ocular trauma score of 51 (19.5). There was no statistical difference in initial VA between types of injury $(P=0.18)$.

Characteristics of injured eye are presented in Table 2, only three (3\%) developed endophthalmitis.

Overall, the mean (SD) of admission duration was 10.2 (5.8) days. Primary wound repaired was performed in $97 / 102$ (95.1\%) eyes, the remaining five eyes presented with self-sealed wounds. Fifty-four eyes $(54 / 102,52.9 \%)$ required two or more surgical interventions. Posterior segment surgery was done in 52/102 (50.9\%) eyes. Enucleation/evisceration was eventually performed in 13/102 (12.7\%) eyes.

Secondary glaucoma was detected in 10/102 (9.8\%) eyes. The median (IQR) final LogMAR VA, 1.7 (0.3 to 3.0), was significantly improved compared to the presenting VA, $P<0.001$. The improvement of final VA was found in 56/102 (54.9\%) eyes, on the contrary, 19/102 (18.6\%) eyes achieved worsening of the final vision. Thirty eyes $(29.4 \%)$ achieved final VA of $20 / 40$ or better, whereas 27 eyes $(26.5 \%)$ acquired no perception of light (NPL). In addition, among those presenting with initial NPL, 12/15 (80\%) eyes remained NPL, $2 / 15(13.3 \%)$ recovered to perception of light, and 1/15 (6.7\%) regained to hand movement following treatments.

With multivariable regression analysis, presence of RAPD (Odds ratio, 3.877; 95\% confidence interval, $1.173-12.816 ; P=0.026$ ) and presence of retinal detachment (Odds ratio, 5.724; $95 \%$ confidence interval, 1.352-24.223; $P=0.018$ ) were significant factors for a poor final VA.

\section{Discussion}

This study found that automobiles were the main vehicle and being a teenager was the risky group for the occurrence of road traffic-related OGI in Northern Thailand. Penetration by pieces of glass and being hit by part of vehicle were the most frequent associated causative mechanisms. The presence of RAPD and retinal detachment were found to be significant predictors at the initial examination for poor final visual outcome.

The impact of road traffic accidents has been evaluated in several hospitalized eye trauma studies. In Taiwan, Lee et al. demonstrated that the main cause for both principal (20.4\%) and secondary diagnosis 
(47.2\%) of admitted eye trauma was traffic accident [7]. In China, Qi et al. pointed out that almost a quarter of hospitalized eye injury (24.2\%) occurred from vehicle-related accidents [8]. Nevertheless, when considering the overall incidence of road traffic-related OGI which attained a poorer visual prognosis compared to closed globe injury, the variation in incidence according to countries has been published [9]. In high-income countries, a low incidence of road traffic accidents has been shown which included a study by Li et al. (2\%) from Hong Kong, Beshay et al. (2\%) from Australia, Fujikawa et al. (3.4\%) from Japan, Court et al. (3.4\%) from New Zealand, and Orr et al. (4\%) from US [3, 14, 15, 20, 21]. In contrary, a much higher incidence has been reported in a study by Madhusudhan et al. (17.6\%) from Malaysia and, accordingly, in this study (9.4\%) which were both characterized as middle-income countries [12]. With a relatively high incidence of road traffic-related eye injuries in this region, it is essential to have more actions from the government and community to make the road safer. However, to establish effective enforcement of a road safety system, it is reasonable to properly define the vulnerable risk groups and investigate related consequences following eye injury.

Considering about gender, the result of this study is consistent with other OGI publications, either investigated for overall causes or only for traffic-related injury, which found that male was a major proportion of patients than female, even though varying in ratio $[13,15,16,20,22]$. This may refer to differences in physical activities between genders. Therefore, public awareness for road safety legislation should be promoted to better understanding among the population, particularly males. Apart from gender, specific age range has been observed to differ between causes of OGI. In fall down-related OGI, the peak incidence has been described in young children and elderly, while patients between 30 to 40 years were at increased risk for occupational-related OGI $[3,4,16,23]$. Nevertheless, in road traffic-related OGI, the disparities in age range have been demonstrated. A study in US by Orr et al. presented that nearly half of cases (48\%) were young patients between 20 to 40 years whereas a study in Japan by Okamoto et al. found that road traffic injury comprised a more proportion of elderly patients with a mean age of 50 years $[20,22]$. This study, similar to Zhang et al., demonstrated that the highest incidence occurred in young patients between 20 to 39 years which represented teenagers and/or early working groups [10]. This finding is in line with a previous report in Thailand which showed that the most commonly admitted road traffic injured age group was 15 to 30 years old [24]. The less experienced in vehicle-related performance and an easily distracted nature might possibly explain the high incidence of injury in this age range. Then, strategies to encourage the use of safety equipment and follow the safety instructions involving vehicle transportation should be emphasized.

Types of vehicle is another factor that should be accounted for. A study by Orr et al. reported that nearly all cases $(96 \%)$ were injured by automobiles and the minority were $(4 \%)$ injured by motorcycles [20]. Okamoto et al noted that the two most frequent injuries were related to car driving (36\%) and bicycle riding (14\%), while the minority were related to motorcycle riding (7\%) [22]. However, this study revealed that the proportion of transportation modes varied by age range. Motorcycles were the most prevalent in the young while the automobiles were the most frequent in adult and elderly. Regular inspection of safety behaviors during riding/driving including seat belt using, helmet wearing, speed limitation, and nonalcohol or non-mobile phone might benefit for injury prevention across all age groups. 
About the mechanism of injury, there were pieces of evidence that globe rupture was the most prevalent type (60 to $64 \%)$ in road traffic-related OGI $[20,22]$. This study noted that a similar proportion of patients sustained injuries from globe rupture and penetration (47 versus $45 \%$ ). This may refer to the nature of road traffic accidents with a higher chance to obtain diffuse ocular damages by both blunt forces, including hit by vehicle parts or road-related construction, and sharp penetration by objects such as glass. On the contrary, most work-related OGI studies have shown that penetration was the most common mechanism $[4,23]$. The high proportion of ruptures may partly explain a low visual potential. In this study, even though VA was significantly improved when comparing final to initial visits, $46 \%$ of the patients achieved final vision worse than 20/200. Consequently, aiming for prevention combined with prompt treatment should be an effective way to reduce severe visual impairment from road traffic-relate OGI.

This study had some limitations due to its retrospective design. As such, detailed information regarding patient and injury severity may under or overestimated. Furthermore, as this is a hospital-based study, it might not represent the minor injured population. However, the results point out several aspects of road traffic OGI characteristics in a middle-income country that should be of concern.

\section{Declarations}

\section{Availability of Data and Materials}

The datasets used and/or analyzed in this study are available from the corresponding author on reasonable request.

\section{Ethics approval}

This study adhered to the tenets of the Declaration of Helsinki. This study was approved by the Research and Ethics Committee, Faculty of Medicine, Chiang Mai University.

\section{Consent for publication}

Not applicable.

\section{Competing interests}

The authors declare that they had no competing interest.

\section{Funding}

This study received funding support from Faculty of Medicine Endowment Fund, Chiang Mai University, Thailand.

\section{Authors Information}

\section{Affiliations}




\section{Contributions}

PU contributed to literature search, data analysis, data interpretation, and writing manuscript. PS contributed to literature search, data collection, data analysis, and writing manuscript. JC contributed for literature search, data analysis, data interpretation, and writing manuscript. All authors have read and approved the final manuscript.

\section{Corresponding author}

Correspondence to Janejit Choovuthayakorn

\section{Acknowledgements}

Not applicable.

\section{Abbreviations}

BETT: the Birmingham Eye Trauma Terminology System

IOFB: intraocular foreign body

IQR: interquartile range

LogMAR: Logarithm of the Minimum Angle of Resolution

NPL: no perception of light

OGI: open globe injury

RAPD: relative afferent pupillary defect

SD: standard deviation

VA: visual acuity

\section{References}

1. Parver LM, Dannenberg AL, Blacklow B, Fowler CJ, Brechner RJ, Tielsch JM. Characteristics and causes of penetrating eye injuries reported to the National Eye Trauma System Registry, 1985-91. Public Health Rep. 1993;108(5):625-32.

2. Wong TY, Tielsch JM. A population-based study on the incidence of severe ocular trauma in Singapore. Am J Ophthalmol. 1999;128(3):345-51. 
3. Court JH, Lu LM, Wang N, McGhee CNJ. Visual and ocular morbidity in severe open-globe injuries presenting to a regional eye centre in New Zealand. Clin Exp Ophthalmol. 2019;47(4):469-77.

4. Kanoff JM, Turalba AV, Andreoli MT, Andreoli CM. Characteristics and outcomes of work-related open globe injuries. Am J Ophthalmol. 2010;150(2):265-69.e2.

5. Bauza AM, Emami P, Soni N, Holland BK, Langer P, Zarbin M, et al. A 10-year review of assault-related open-globe injuries at an urban hospital. Graefes Arch Clin Exp Ophthalmol. 2013;251(3):653-9.

6. Morikawa S, Okamoto F, Okamoto Y, Inomoto N, Ishikawa H, Ueda T, et al. Clinical characteristics and visual outcomes of sport-related open globe injuries. Acta Ophthalmol. 2018;96(7):e898-e9.

7. Lee JS, Chiou MJ, Teng FL, See LC. The role of principal and secondary diagnoses of hospitalized eye trauma: a nationwide cohort in Taiwan, 1996-2010. PLoS One. 2015;10(4):e0123348.

8. Qi Y, Zhang FY, Peng GH, Zhu Y, Wan GM, Wang WZ, et al. Characteristics and visual outcomes of patients hospitalized for ocular trauma in central China: 2006-2011. Int J Ophthalmol. 2015;8(1):1628.

9. Wang W, Zhou Y, Zeng J, Shi M, Chen B. Epidemiology and clinical characteristics of patients hospitalized for ocular trauma in South-Central China. Acta Ophthalmol. 2017;95(6):e503-e10.

10. Zhang X, Liu Y, Ji X, Zou Y. A Retrospective study on clinical features and visual outcome of patients hospitalized for ocular trauma in Cangzhou, China. J Ophthalmol. 2017;2017:7694913.

11. Iftikhar M, Latif A, Farid UZ, Usmani B, Canner JK, Shah SMA. Changes in the incidence of eye trauma hospitalizations in the United States from 2001 through 2014. JAMA Ophthalmol. 2019;137(1):48-56.

12. Madhusudhan AP, Evelyn-Tai LM, Zamri N, Adil H, Wan-Hazabbah WH. Open globe injury in hospital universiti Sains Malaysia - A 10-year review. Int J Ophthalmol. 2014;7(3):486-90.

13. Page RD, Gupta SK, Jenkins TL, Karcioglu ZA. Risk factors for poor outcomes in patients with openglobe injuries. Clin Ophthalmol. 2016;10:1461-6.

14. Li EY, Chan TC, Liu AT, Yuen HK. Epidemiology of open-globe injuries in Hong Kong. Asia Pac J Ophthalmol (Phila). 2017;6(1):54-8.

15. Fujikawa A, Mohamed YH, Kinoshita H, Matsumoto M, Uematsu M, Tsuiki E, et al. Visual outcomes and prognostic factors in open-globe injuries. BMC Ophthalmol. 2018;18(1):138.

16. Okamoto Y, Morikawa S, Okamoto F, Inomoto N, Ishikawa H, Ueda T, et al. Clinical characteristics and outcomes of open globe injuries in Japan. Jpn J Ophthalmol. 2019;63(1):109-18.

17. Pieramici DJ, Sternberg P Jr, Aaberg TM Sr, Bridges WZ J., Capone A Jr, Cardillo JA, et al. A system for classifying mechanical injuries of the eye (globe). The Ocular Trauma Classification Group. American journal of ophthalmology. 1997;123(6):820-31.

18. Kuhn F, Maisiak R, Mann L, Mester V, Morris R, Witherspoon CD. The Ocular Trauma Score (OTS). Ophthalmology clinics of North America. 2002;15(2):163-5, vi.

19. Kuhn F, Morris R, Witherspoon CD, Mester V. The Birmingham Eye Trauma Terminology system (BETT). J Fr Ophtalmol. 2004;27(2):206-10. 
20. Orr CK, Bauza A, Langer PD, Zarbin MA, Bhagat N. Open-globe injuries with motor vehicle accidents: a 12-year review. Graefes Arch Clin Exp Ophthalmol. 2015;253(8):1313-7.

21. Beshay N, Keay L, Dunn H, Kamalden TA, Hoskin AK, Watson SL. The epidemiology of open globe injuries presenting to a tertiary referral eye hospital in Australia. Injury. 2017;48(7):1348-54.

22. Okamoto Y, Morikawa S, Okamoto F, Mitamura Y, Ishikawa H, Ueda T, et al. Traffic accident-related open globe injuries. Retina. 2019;39(4):779-85.

23. Bauza AM, Emami P, Son JH, Langer P, Zarbin M, Bhagat N. Work-related open-globe injuries: demographics and clinical characteristics. Eur J Ophthalmol. 2013;23(2):242-8.

24. Chadbunchachai W, Suphanchaimaj W, Settasatien A, Jinwong T. Road traffic injuries in Thailand: current situation. J Med Assoc Thai. 2012;95 Suppl 7:S274-81.

\section{Tables}

Table 1 Demographics of Road Traffic-related Open Globe Injury Patients 


\begin{tabular}{|c|c|}
\hline Characteristics of Patients & Number, $\mathbf{N}(\%)$ \\
\hline \multicolumn{2}{|l|}{ Gender } \\
\hline Male & $72(78.3)$ \\
\hline Female & $20(21.7)$ \\
\hline \multicolumn{2}{|l|}{ Age group } \\
\hline$<20$ years & $16(17.4)$ \\
\hline $20-39$ years & $47(51.1)$ \\
\hline $40-59$ years & $24(26.1)$ \\
\hline$\geq 60$ years & $5(5.4)$ \\
\hline \multicolumn{2}{|l|}{ Laterality } \\
\hline Unilateral & $82(89.1)$ \\
\hline Bilateral & $10(10.9)$ \\
\hline \multicolumn{2}{|l|}{ Status } \\
\hline Pedestrian & $3(3.3)$ \\
\hline Car driver/passenger & $54(58.7)$ \\
\hline Motorcycle rider/passenger & $30(32.6)$ \\
\hline Unknown & $5(5.4)$ \\
\hline \multicolumn{2}{|l|}{ Causative Objects (102 eyes) } \\
\hline Broken glass & $42(41.2)$ \\
\hline Blunt object/vehicle part & $39(38.2)$ \\
\hline Metal object & $8(7.8)$ \\
\hline Wood & $2(2)$ \\
\hline Unknown & $11(10.8)$ \\
\hline
\end{tabular}

Table 2 Ocular Characteristics of Road Traffic-related Open Globe Injury 


\begin{tabular}{|c|c|}
\hline Characteristics & Eye, N (\%) \\
\hline \multicolumn{2}{|l|}{ Zone of injury } \\
\hline I & $21(20.8)$ \\
\hline II & $41(40.6)$ \\
\hline III & 39 (38.6) \\
\hline \multicolumn{2}{|l|}{ Wound length } \\
\hline$\leq 10 \mathrm{~mm}$ & $50(49.5)$ \\
\hline$>10 \mathrm{~mm}$ & 49 (48.5) \\
\hline Unknown & $2(2)$ \\
\hline \multicolumn{2}{|l|}{ Initial VA } \\
\hline $20 / 40$ and better & $6(5.9)$ \\
\hline $20 / 50$ to $20 / 200$ & $4(3.9)$ \\
\hline $19 / 200$ to projection of light & $73(71.5)$ \\
\hline No perception of light & $16(15.7)$ \\
\hline Cannot be assessed & $3(2.9)$ \\
\hline Presence of RAPD & $45(50.6)$ \\
\hline Hyphema & $56(55.4)$ \\
\hline Lens injury & $53(52.5)$ \\
\hline Uveal tissue prolapse & $56(55.4)$ \\
\hline Vitreous prolapse & $31(30.7)$ \\
\hline Vitreous hemorrhage & $51(50.5)$ \\
\hline \multicolumn{2}{|l|}{ Retinal injury } \\
\hline Retinal detachment & $36(35.6)$ \\
\hline Retinal break & $6(5.9)$ \\
\hline Commotio retinae & $2(2.0)$ \\
\hline Choroidal injury & $22(21.8)$ \\
\hline \multicolumn{2}{|l|}{ Adnexal injury } \\
\hline Eye lid injury & $37(36.6)$ \\
\hline Orbital injury & $7(6.9)$ \\
\hline
\end{tabular}


Both lid and orbital injury

$13(12.9)$

Presence of endophthalmitis

$3(3.0)$

Ocular trauma score class

Class 1 (0-44)

29 (28.7)

Class 2 (45-65)

41 (40.6)

Class 3 (66-80)

$23(22.8)$

Class 4 (81-91)

$2(2)$

Class 5 (92-100)

3 (3)

Cannot be assessed

$3(3)$

$V A=$ visual acuity, $R A P D=$ relative afferent pupillary defect

Figures

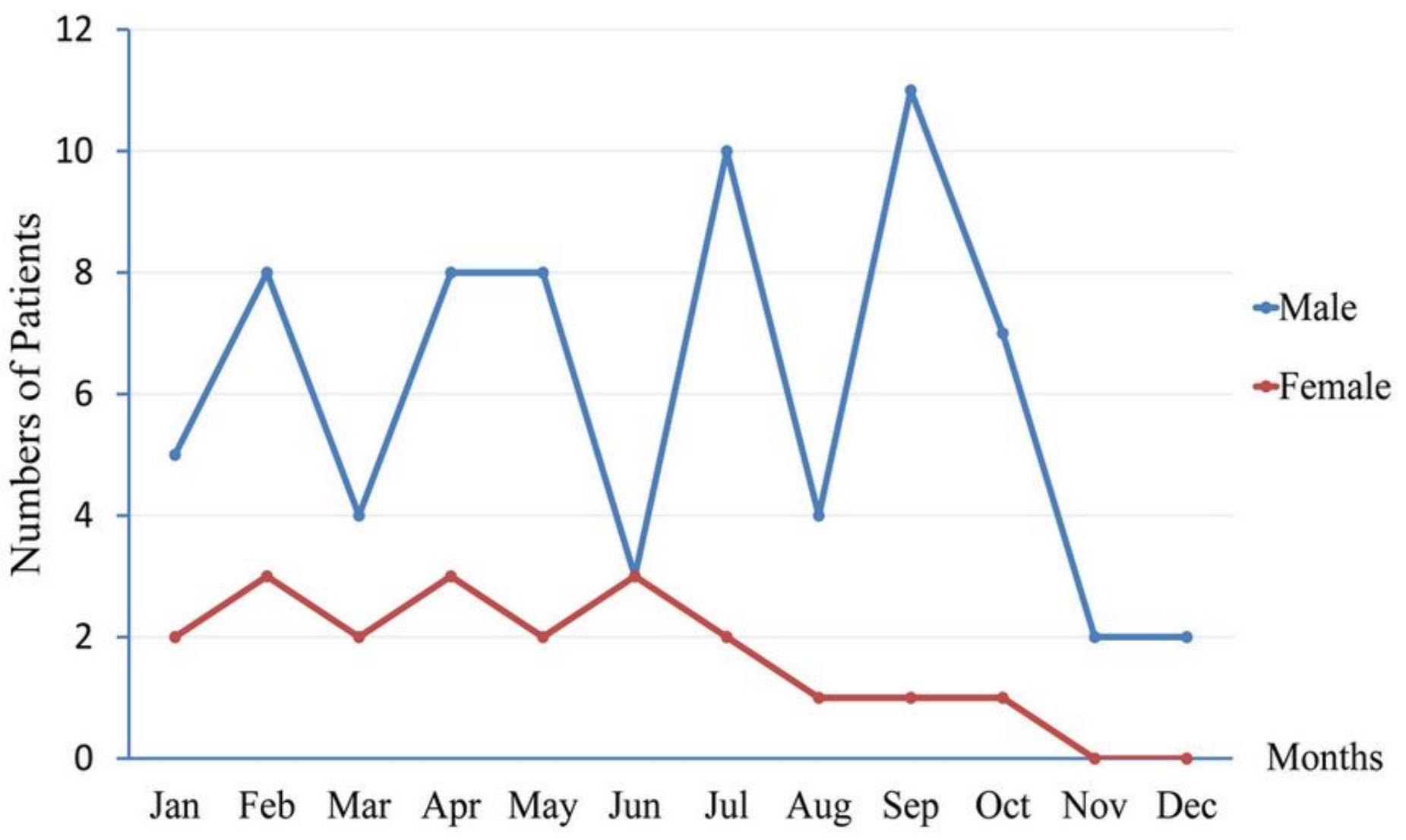


Figure 1

Incidence of Road Traffic-related Opened Glove Injury by Gender and Month of a Year

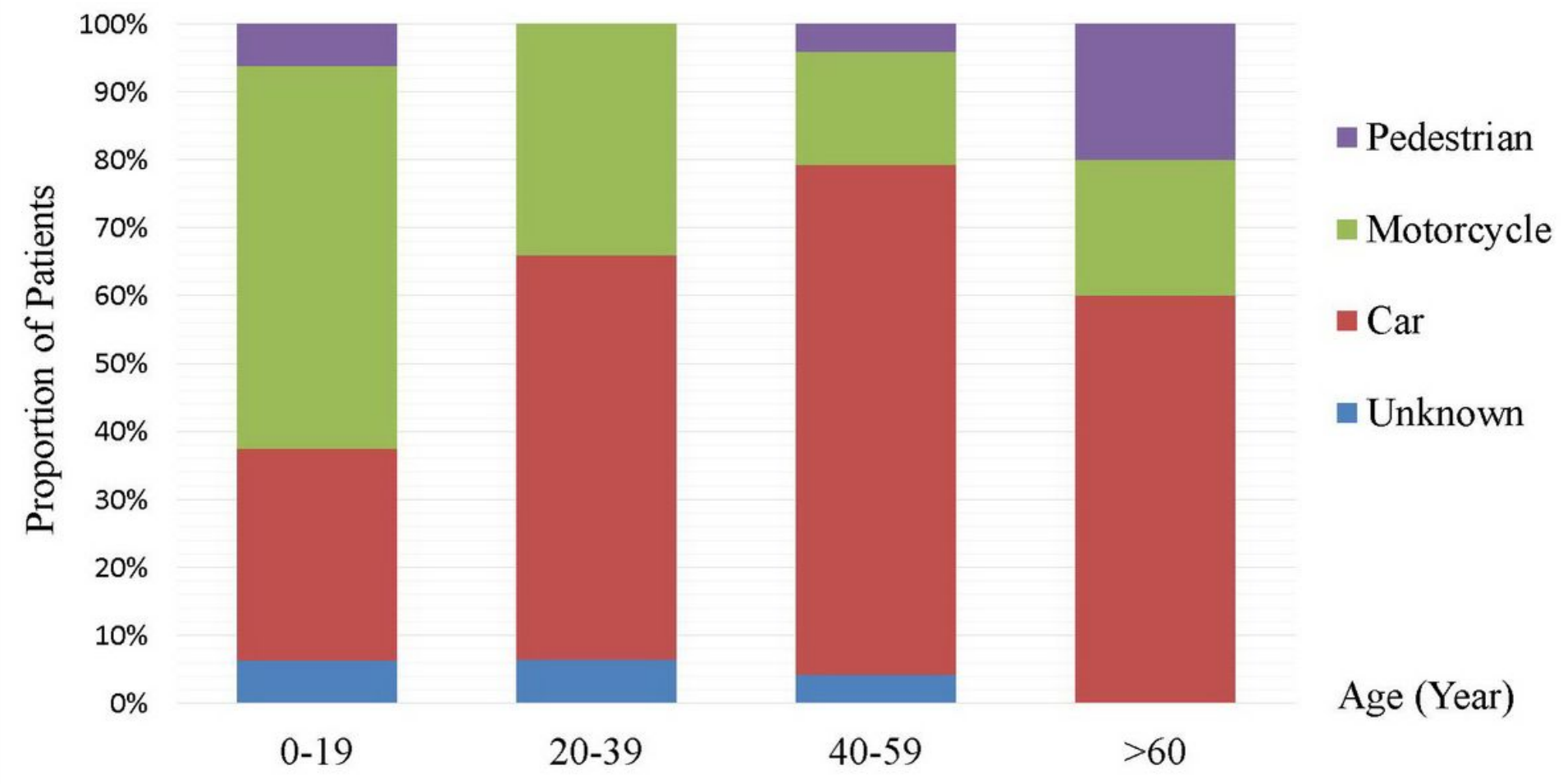

\section{Figure 2}

Distribution of Vehicle Modes Involving in Injury by Age Groups 